\title{
Statement on smoking cessation in COPD and other pulmonary diseases and in smokers with comorbidities who find it difficult to quit
}

\author{
Carlos A. Jiménez-Ruiz ${ }^{1}$, Stefan Andreas ${ }^{2}$, Keir E. Lewis ${ }^{3}$, Philip Tonnesen ${ }^{4}$, \\ C.P. van Schayck ${ }^{5}$, Peter Hajek ${ }^{6}$, Serena Tonstad ${ }^{7}$, Bertrand Dautzenberg ${ }^{8}$, \\ Monica Fletcher ${ }^{9}$, Sarah Masefield ${ }^{10}$, Pippa Powell ${ }^{10}$, Thomas Hering ${ }^{11}$, \\ Stefano Nardini ${ }^{12}$, Thomy Tonia ${ }^{13}$ and Christina Gratziou ${ }^{14}$
}

Affiliations: ${ }^{1}$ Smoking Cessation Service, Community of Madrid, Madrid, Spain. ${ }^{2}$ Lungenfachklinik Immenhausen and Pneumology, Universitätsmedizin Göttingen, Göttingen, Germany. ${ }^{3}$ Dept of Respiratory Medicine, Prince Philip Hospital and Swansea College of Medicine, Swansea, UK. ${ }^{4}$ Dept of Sleep Medicine, Glostrup Hospital, Glostrup, Denmark. ${ }^{5}$ Care and Public Health Research Institute (Caphri), Maastricht University, Maastricht, The Netherlands. ${ }^{6}$ Wolfson Institute of Preventive Medicine, Queen Mary University of London, London, UK. ${ }^{7}$ Section for Preventive Cardiology, Oslo University Hospital, Oslo, Norway. ${ }^{8}$ Pulmonology, Groupe Hospitalier PitieSalpetriere, France. ${ }^{9}$ Education for Health, Warwick, UK. ${ }^{10}$ European Lung Fundation, Sheffield, UK. ${ }^{11}$ Lungenarztpraxis Tegel, Berlin, Germany. ${ }^{12}$ Pulmonary and TB Unit, Ospedale Civile, Vittorio Veneto, Italy. ${ }^{13}$ Institute of Social and Preventive Medicine, University of Bern, Switzerland. ${ }^{14}$ University Centre for Research and Smoking Cessation, Evgenidio Hospital, Medical School, Athens University, Athens, Greece.

Correspondence: Carlos A. Jimenez-Ruiz, Smoking Cessation Service, Community of Madrid, Spain. C/ Santacruz del Marcenado, 9. Piso 2, 28015 Madrid, Spain. E-mail: victorinalactv.es

ABSTRACT Chronic obstructive pulmonary disease (COPD), lung cancer, asthma and pulmonary tuberculosis are common pulmonary diseases that are caused or worsened by tobacco smoking. Growing observational evidence suggests that symptoms and prognosis of these conditions improve upon smoking cessation. Despite increasing numbers of (small) randomised controlled trials suggesting intensive smoking cessation treatments work in people with pulmonary diseases many patients are not given specific advice on the benefits or referred for intensive cessation treatments and, therefore, continue smoking.

This is a qualitative review regarding smoking cessation in patients with COPD and other pulmonary disorders, written by a group of European Respiratory Society experts. We describe the epidemiological links between smoking and pulmonary disorders, the evidence for benefits of stopping smoking, how best to assess tobacco dependence and what interventions currently work best to help pulmonary patients quit. Finally, we describe characteristics and management of any "hardcore" smoker who finds it difficult to quit with standard approaches.

@ERSpublications

Smoking cessation is crucial for respiratory patients: every patient must be given advice and help to quit http://ow.ly/ITgsW 


\section{Methodology}

This document was written as part of an initiative from a European Respiratory Society (ERS) Task Force with methodological support from ERS. We followed the following procedures.

1) C. Jiménez-Ruiz, P. Tonnesen and K. Lewis searched MEDLINE between January 1, 2002 and December 31, 2013. The keywords describing the patient population were "chronic obstructive pulmonary disease", "chronic obstructive lung disease", "emphysema", "COPD”, "chronic bronchitis", "lung cancer", "bronchial cancer", "thoracic cancer", "asthma", "tuberculosis" and "pulmonary tuberculosis". The keywords describing smoking cessation interventions were "smoking", "smoking cessation", "tobacco", "tobacco use cessation", "smoking cessation programme", and "quit". Studies were included according to the following criteria: 1) dealing with patients with chronic obstructive lung disease (COPD) or lung cancer or asthma or tuberculosis (TB); 2) randomised controlled trials (RCTs) and longitudinal studies; 3) evaluation of a smoking cessation intervention; and 4) published in English.

2) Based on the included studies, C. Jiménez-Ruiz, S. Andreas, K. Lewis and P. Tonnesen produced a first manuscript providing a narrative review of the selected studies. The manuscript was circulated among all members of the Task Force. Each member added comments and suggestions to this manuscript. K. Lewis and C. Jiménez-Ruiz led the redrafting following the reviewer's comments.

3) The first manuscript was revised according to the comments and suggestions from all Task Force members and recirculated.

4) Finally, the manuscript obtained approval from all members of the Task Force. This document is a statement on smoking cessation in COPD and other pulmonary diseases, and the management of smokers with comorbidities that find it difficult to quit.

\section{Introduction}

Two previous ERS documents concerning smoking exist: the CEASE (Collaborative European Anti-Smoking Evaluation) trial conducted on behalf of ERS by the Occupational and Epidemiology Assembly [1]; and the report from another ERS Task Force on smoking cessation in patients with respiratory diseases by TøNNESEN et al. [2], from 2007. The main conclusions from CEASE trial were as follows: a higher than standard dose of nicotine patch was associated with an increase in the long-term success of smoking cessation, but continuation of treatment beyond $8 \pm 12$ weeks did not increase the success rates [1]. The main conclusions from the 2007 ERS Task Force were as follows. 1) Patients with respiratory disease have a greater and more urgent need to stop smoking than the average smoker, so respiratory physicians must take a proactive and continuing role with all smokers in motivating them to stop and in providing treatment to aid smoking cessation. 2) Smoking cessation treatment should be integrated into the management of the patient's respiratory condition. 3) Therapies should include pharmacological treatment (i.e. nicotine replacement therapy (NRT), bupropion or varenicline) combined with behavioural support. 4) Respiratory physicians should receive training to ensure that they have the knowledge, attitudes and skills necessary to deliver these interventions or to refer to an appropriate specialist. 5) Although the cost of implementing these recommendations will partly be offset by a reduction in attendance for exacerbations, etc., a budget should be established to enable implementation [2].

More recently, the SmokeHaz website has been created [3]. SmokeHaz is a collaboration between ERS and the UK Centre for Tobacco and Alcohol Studies. The two organisations agreed to join forces, and work with the European Lung Foundation, to provide a website aimed at policymakers primarily focused on the respiratory health hazards associated with smoking. The aim of the SmokeHaz website is to provide a one-stop web platform assessing the relationship between active and passive smoking and a range of specific health outcomes, particularly focusing on lung health. Robust methods were used to gather together all of the available scientific studies that provided an unbiased account of the true relationship between smoking and health. These methods included systematic reviews and meta-analyses [3].

This statement follows in this tradition, with the aim to provide an up-to-date review of current developments in this field.

\section{Smoking cessation in patients with COPD \\ Smoking as a cause of COPD}

COPD is a progressive, multisystem inflammatory disease characterised by airflow limitation. It is one of the most common respiratory disorders with a prevalence of $8-13 \%$ among adults in Europe and North America with many remaining undiagnosed $[4,5]$. The prevalence is increasing and rises with age $[4,5]$.

There is a strong relationship between smoking and the development of COPD. $40 \%$ of COPD patients in the developed world are smokers or ex-smokers. Epidemiological studies show that smoking is linked to 
a deterioration of pulmonary function $[6,7]$. Smoking during adolescence inhibits the normal expansion of pulmonary function during growth and the forced expiratory volume in $1 \mathrm{~s}$ (FEV1) later in life [8]. Smoking lowers the age at which FEV1 begins to decline [9], and also accelerates the annual decrease of FEV1 in late adulthood $[7,10,11]$.

Smoking cessation remains the most effective intervention that reduces lung function decline in COPD [12], slowing the annual decrease of FEV1 to a rate comparable with that of nonsmokers $[6,13]$. FEV1 initially increases after smoking cessation $[9,14]$ and quitters show a better response to bronchodilators [11] and inhaled corticosteroids (ICS) [15].

Nevertheless, $\sim 40 \%$ of COPD patients remain smokers. In a recent multicentre, interventional study of bronchodilator therapy $40 \%$ of participants with established moderate-to-severe COPD were current smokers [16]. Similar data have been reported from epidemiological studies [17, 18].

\section{Characteristics of smokers with COPD}

Smokers with COPD have specific features that may make it harder for them to quit [17-19]. Two studies reported that smokers with COPD scored higher on the Fagerström Test for Nicotine Dependence (FTND) and that the number of cigarettes smoked daily was significantly higher compared with smokers without COPD $[17,18]$. Another study found that each additional FTND point was associated with an increase of $11 \%$ in the probability of developing COPD [19]. These results suggest that smokers with COPD are more nicotine dependent, but it is also possible that persons with a higher degree of dependence run a higher chance of developing COPD.

Some studies report smokers with COPD inhale a greater volume of smoke and inhale more deeply than smokers without COPD, so more toxic substances reach the lungs [12]. This is perhaps confirmed by the observation that smokers with COPD had higher expired carbon monoxide (eCO) levels than healthy smokers (although this was not statistically significant in the multivariate model) [17].

Some studies report no difference in motivation to quit between smokers with COPD and other smokers, but smokers with COPD report less self-efficacy and self-esteem impairing their ability to stop [20]. Co-existent depression was reported in $44 \%$ of (hospitalised) patients with COPD and depression is more common among smokers with COPD than in other smokers [21]. A vicious circle may result with smoking leading to COPD, and COPD to depression which itself has a negative impact on cessation in these smokers [21].

Weight gain is frequently associated with smoking cessation, but we could find no studies regarding weight gain in quitters with COPD. The adverse effect of any weight gain (on average 5-6 kg over 6 months in healthy smokers) on lung function is likely to be minimal, especially when the benefits of cessation are considered. Moreover, in underweight patients with COPD some weight gain is desirable.

In summary, many smokers with COPD have specific characteristics that reduce their chance of quitting successfully (table 1).

\section{Assessment and recording of smoking status in patients with COPD}

Several variables are associated with a successful quit in COPD. These include fewer cigarettes smoked daily, fewer years of smoking, more motivation to quit, more self-efficacy, less dependence, less depression and earlier smoking cessation experiences (fig. 1).

Assessment of the number of cigarettes smoked daily in smokers with COPD

Healthcare professionals ask all patients, including those with COPD, about smoking to assess risk and tailor treatment. For the first assessment, healthcare professionals elicit the number of cigarettes smoked daily and the number of years of smoking. Usually, cigarette consumption correlates very strongly with the risk of developing COPD, a worse stage of COPD [12] and faster progression [12, 18, 19, 22].

Alongside smoking index (in pack-years), eCO can be good indicator of the amount of smoking. Nonsmokers typically have readings between 3 and $6 \mathrm{ppm}$, while readings for smokers are generally $10 \mathrm{ppm}$ or more,

TABLE 1 Benefits of smoking cessation in chronic obstructive pulmonary disease (COPD)

Smoking cessation is the most effective measure for controlling the progression of COPD

Smoking cessation reduces the annual decrease of forced expiratory volume in $1 \mathrm{~s}$

Smoking cessation improves responses to bronchodilator drugs and inhaled corticosteroids

Smoking cessation reduces the incidence of acute exacerbations

Smoking cessation reduces bronchial infections 


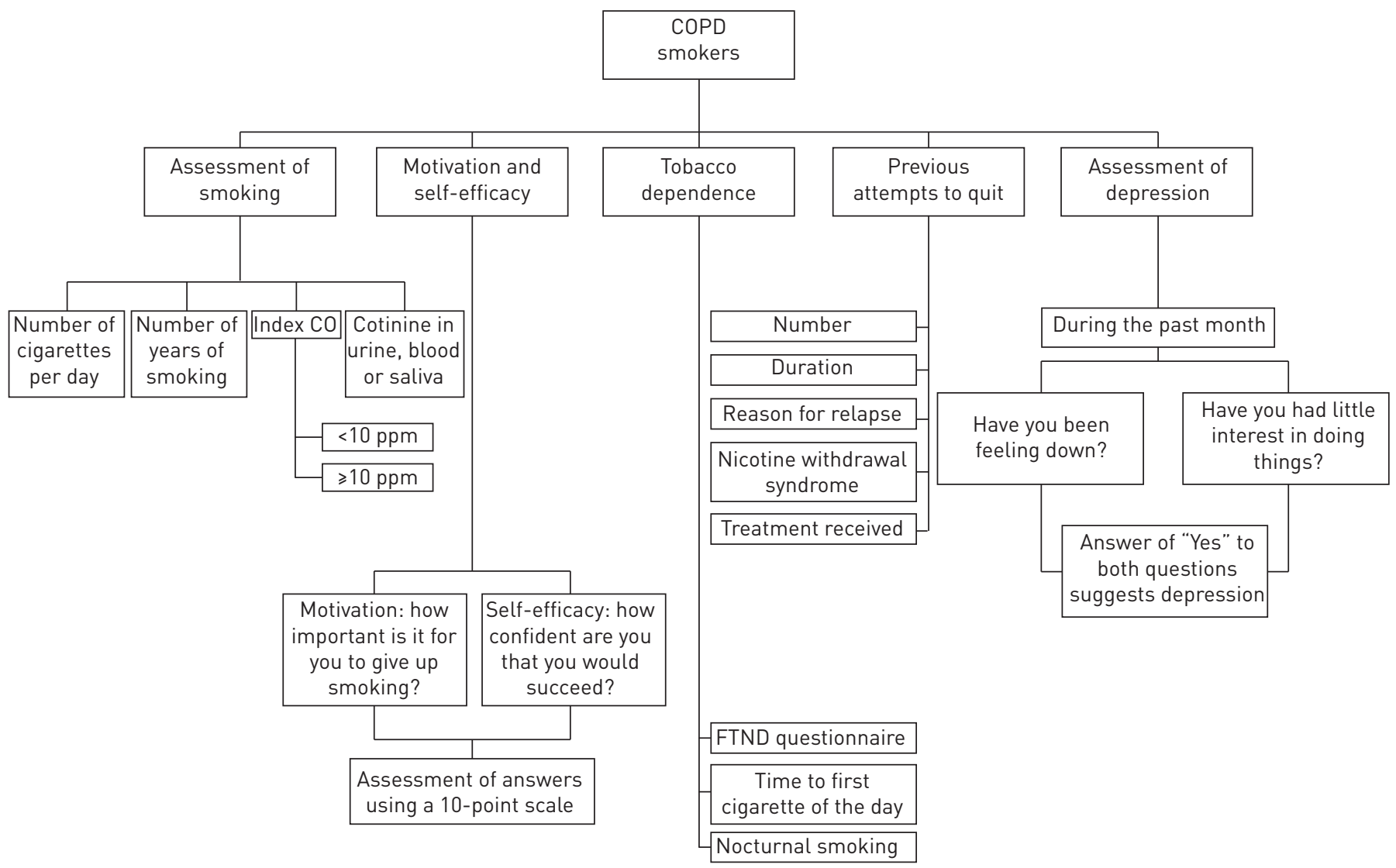

FIGURE 1 Assessment and recording of smoking status in patients with chronic obstructive pulmonary disease (COPD). FTND: Fagerström Test for Nicotine Dependence.

depending on the timing, number of cigarettes smoked and pattern of smoking. Passive smoking does not usually put the reading over $10 \mathrm{ppm}$, but shisha smoke exposure, cannabis use, faulty car exhausts, working with paint stripper, faulty gas boilers and lactose intolerance can increase eCO levels and complicate interpretation. CO monitors may be useful both to verify smoking status and to illustrate early potential health benefits [23].

A CO monitor may be used to tailor disease specific advice to COPD patients:

"CO is one of the gases that you inhale when you smoke cigarettes. It displaces oxygen from your red blood cells worsening breathlessness. Cigarettes also damage your lungs over time. If you quit smoking, your CO levels will drop to normal within 24 h.”

Subsequent clinic visits have a different emphasis. Continuing smokers may be worried because they more clearly understand that smoking is impairing their health, they may use denial as a defence mechanism or be reluctant to admit to continuing to smoke. In these situations, healthcare professionals should remain empathetic and demonstrate respect by using questions such as: "What are your thoughts about smoking at this time?" Answers are frequently validated, usually with eCO levels.

\section{Assessment of motivation and self-efficacy in smokers with COPD}

Smokers with COPD usually have low self-efficacy [20] and are less motivated to quit than other smokers, both factors associated with low quit rates $[20,24]$. Increasing motivation and building self-efficacy are particularly important for this group of patients. Unfortunately, validated measures for assessing the degree of motivation to quit have not yet been developed. A simple way of assessing willingness to quit is to ask:

"How important is it for you to give up smoking?"

The smoker answers according to a 10-point scale, with zero being of no importance and 10 being extremely important. Further information can be obtained through motivational interviewing techniques:

"You responded that your motivation was at a two. What would need to happen for you to get from your current two to an eight?" 
Likewise, self-efficacy can be assessed by asking:

"If you were to stop smoking how confident are you that you would succeed?" [25].

If readiness to quit and confidence are good, a quit date is usually set immediately. If motivation is high but self-efficacy is low, treatment and support are very critical for success. If self-efficacy is high but willingness to try is low, effective health education and motivational interviewing [24] are more critical. If both are low, then more intensive support is needed.

\section{Assessment of tobacco dependence in smokers with COPD}

Knowing the degree of tobacco dependence and reinforcers that maintain smoking in COPD are crucial. Three questionnaires are commonly used to measure dependence: the FTND questionnaire, the World Health Organization International Classification of Diseases and Injuries, and the Cigarette Dependence Scale [26-28]. The FTND is the most widely used of these scales and predicts difficulty of quitting, severity of withdrawal symptoms and need for pharmacological treatment [29].

Another helpful approach is an understanding of what motivates a smoker to continue: negative reinforcement (i.e. to avoid unpleasant withdrawal symptoms) appears to be more frequent than positive reinforcement (pleasure) among smokers with COPD [30-32].

Some smokers with COPD smoke a low number of cigarettes per day despite a high degree of nicotine dependence. A frequently used method to measure dependence is asking about the time to their first cigarette after waking up. Smokers who start within $30 \mathrm{~min}$ after waking have a high degree of dependence, while those who begin to smoke later appear to be less dependent [33]. Another indicator of high dependence is nocturnal smoking.

\section{Assessment of depression in smokers with COPD}

In smokers with COPD, healthcare professionals proactively ask about depression and assess the level of depression. For example, using two simple questions: 1) during the past month, have you been bothered by feeling down, depressed, or hopeless? 2) during the past month, have you often been bothered by having little interest or pleasure in doing things? An answer of "yes" to either of the questions is a strong sign of depression [34].

Assessment of previous attempt(s) to quit

Knowledge of previous attempts to quit is very important in helping tailor a new quit attempt. Most smokers take 4-7 attempts to successfully quit and many have tried to quit before $[35,36]$. The number of attempts, duration of each abstinence, severity and timing of nicotine withdrawal symptoms, type of psychological support received and the patient's perception of its efficacy, type of pharmacological treatment received and efficacy, and reasons for relapse are often discussed and documented as such information can be useful in guiding treatment.

\section{Smoking cessation treatment in smokers with COPD}

Several meta-analyses confirm that a combination of counselling plus pharmacotherapy is the most effective cessation treatment for smokers with COPD [35-39].

Smoking cessation counselling for smokers with COPD

During the first consultation, smokers with COPD receive firm advice that tobacco smoking is the main or only cause of their illness and current symptoms (table 2). It is important they are informed that: 1) smoking cessation is the only measure that slows the progression of illness and improves prognosis; 2) inhaled treatments will not work as well with continued smoking; and 3) smoking cessation improves airflow obstruction and all of the four core symptoms of COPD (breathlessness, cough, wheeze and chest pain) [40].

Nevertheless, most smokers with COPD have already been advised to stop smoking so may feel patronised and/or be tempted to withhold information. An empathic and non-judgmental relationship where smoking is discussed in a nonthreatening and respectful way is useful. The advice is usually short, and direct: "The best thing you can do to help your COPD is to stop smoking. I can help you with that". This advice is repeated at every follow-up visit. There are no definite advantages to using specific words like "smokers' lung" or providing contingent reinforcement with lottery tickets, when compared with usual advice [20,41]. A common procedure for CO monitoring is that the healthcare professional first exhales into the device, showing a normal CO concentration of 1-4 ppm. Then the smoker blows into the machine, after which she/he immediately sees a much higher reading (average of $10-20 \mathrm{ppm}$ ). Then the healthcare professional emphasises that the high amount of $\mathrm{CO}$ attaches to haemoglobin/blood molecules 
TABLE 2 Characteristics of counselling for smoking cessation in smokers with chronic obstructive pulmonary disease (COPD)

Clear explanation of the relationship between smoking and COPD, and the relationship between smoking cessation and improvement of COPD

Use of spirometric results, CO monitors and "lung age" to increase motivation to quit

Setting a quit date, identifying high-risk situations and developing coping skills

Arranging follow-up visits in order to specifically address smoking cessation

Explanation of the withdrawal syndrome

Providing self-help materials

Sending personal letters, e-mails and SMS

thereby reducing oxygen delivery all over the body. Respiratory nurses have successfully provided repeat and intensive cessation treatments for smokers with COPD [42].

At least one study supports the idea that spirometry increases motivation and even quit rates in smokers with COPD [43], but a meta-analysis found little evidence of benefit of various biomedical risk assessments (including eCO and genetic susceptibility, and eCO with spirometry) when provided in addition to cessation counselling alone [44]. A UK study randomised some smokers to being given their spirometry results described as a "lung age" (the age of the average healthy individual who would perform similar spirometry to them). A control group received a raw figure for FEV1. Both groups were advised to quit and offered referral to local smoking cessation services. $13.6 \%$ of the "lung age" group versus $6.4 \%$ of the FEV1 group quit smoking after 12 months (number needed to treat=14). The cost per successful quitter was estimated at 366 euros [45].

Healthcare professionals encourage their patients to quit immediately if in hospital or to choose a quit date, and identify high-risk situations and development of coping skills. Symptoms of nicotine withdrawal are explained using written information and self-help materials. Follow-up visits are arranged with the main or sole purpose of smoking cessation. A commonly used frequency is the first, second, eighth, 12th, 16th and 24th week after the target quit date. We could find no studies, to date, reporting the use of new technologies (apps, texts, e-mails, etc.) in COPD smokers. Group interventions are equally effective as individual support in COPD [37].

Long-term oxygen therapy assessment and prescribing in COPD provide another opportunity for intensive smoking cessation intervention [46].

\section{Pharmacological treatment for smokers with COPD}

The standard pharmacological treatments are all licensed for smokers with COPD with no additional prescribing limitations (table 3).

\section{Short-acting NRT}

Nicotine gum. The efficacy of nicotine gum in smokers with COPD has been shown in large-scale clinical trials. The Lung Health Study was a multicentre, randomised, controlled trial designed to determine whether a programme incorporating a smoking cessation intervention and regular use of an inhaled bronchodilator in smokers at high risk of COPD slowed the annual decline in FEV1. After 12 months, nicotine gum in combination with an intensive behavioural programme led to significantly more quitters than usual care [52]. Another open-label, randomised study of 446 consecutive smokers with pulmonary disorders (including COPD) compared four different forms of NRT and placebo. The continuous abstinence rates at 12 months follow-up were: placebo $2 \%$, nicotine inhalator $5 \%$, nicotine patches $9 \%$, and nicotine inhalator plus nicotine patches $6 \%$. All active arms were more successful than placebo $(p<0.01)$ [53].

Dosing and duration is the same for COPD as all smokers. For those who smoke $<20$ cigarettes per day, or smoke their first cigarette $>30 \mathrm{~min}$ after waking up, one 2-mg piece of nicotine gum every 1-2 $\mathrm{h}$. For those who smoke $\geq 20$ cigarettes per day, or who smoke their first cigarette within $30 \mathrm{~min}$ of awakening, 4-mg pieces are often used at a similar frequency. Treatment duration ranges from 8 to 12 weeks. For those with high nicotine dependence, medication may be prolonged for up to 6-12 months [54]. Nicotine gum is often used as a rescue medication to control cravings on top of other medication.

Nicotine sublingual tablets. A trial of 370 smokers with COPD compared treatment with sublingual tablets at adequate doses or placebo for 12 weeks, and also examined low and high levels of support. Smoking cessation rates were statistically significantly superior in the active treatment group at 6 and 12 months follow-up (23 versus $10 \%$ and 17 versus 10\%, respectively). There was no significant difference in the effect of NRT between low and high levels of support [47]. 
TABLE 3 Pharmacological treatments for smokers with chronic obstructive pulmonary disease (COPD)

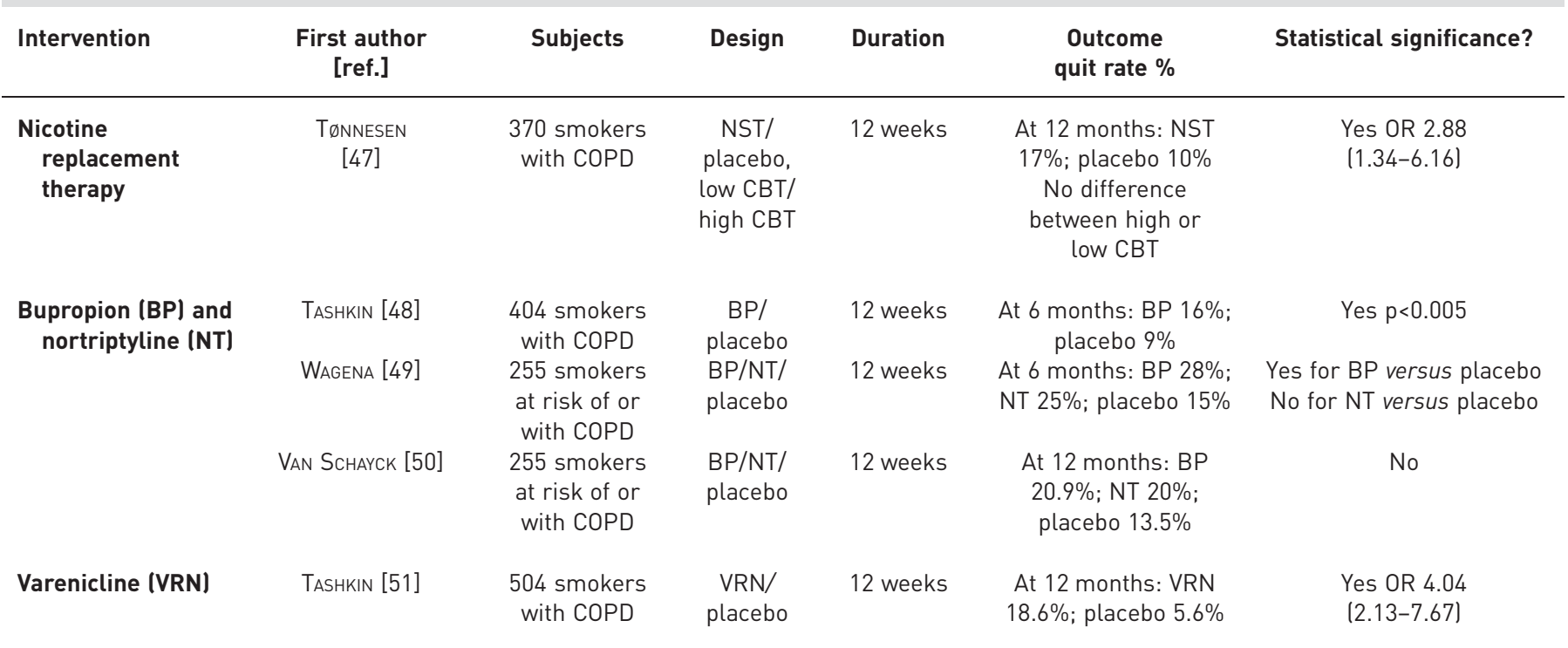

The table only shows randomised, double-blind, placebo-controlled trials. All studies, but VAN ScHarck et al. [50], assessed cessation by measuring $\mathrm{CO}$ in expired air. VAN SCHAYCK et al. [50] assessed cessation by measuring urinary cotinine. NST: nicotine sublingual tablets; CBT: cognitive behavioural therapy.

Other study designs

In a randomised clinical trial, 247 smokers with COPD received a continuous 1-year smoking cessation programme (including a 2 -week period of hospitalisation then trained staff providing feedback and encouraging comments by phone throughout the year), while 231 smokers received usual care. $52 \%$ of smokers in the continuous 1-year smoking cessation programme were abstinent after 1 year and $38 \%$ after 3 years, compared with 7 and 10\%, respectively, in the control group. In spite of the high cost of this programme, beneficial economic effects were likely to be obtained in the long run [55].

Smokers with COPD who are unable or unwilling to set a quit date are advised to use NRT in a reduction-to-quit approach. This method builds self-efficacy and motivation [56]. However, a systematic review of 25 studies in all smokers (including COPD) found that smoking reduction (as opposed to quitting) has fewer quitters and does not appear to slow the accelerated decline of lung function [57]. The lack of beneficial effect of smoking reduction could be explained by compensatory deeper and longer inhalation of smoke $[14,58,59]$, but may still increase cessation rates in the long-term.

Bupropion and nortriptyline. A RCT of 12 weeks of bupropion in 404 smokers with mild or moderate COPD led to a continuous abstinence rate of 16 versus $9 \%$ for placebo at 6 months [48]. Another RCT of 255 smokers with mild or moderate COPD or at risk of COPD found a continuous abstinence rate at 6 months of $28 \%$ for bupropion, $25 \%$ for nortriptyline and $15 \%$ for placebo. The only statistically significant difference was between bupoprion and placebo [49].

A similar study showed prolonged abstinence rates at 1 year of $20.9 \%$ with bupropion, $20.0 \%$ with nortriptyline and $\mathbf{1 3 . 5 \%}$ with placebo but these were not statistically significant. Costs per quitter were 1368 euros with bupropion, 1906 euros with nortriptyline and 1212 euros with placebo [50].

A meta-analysis of 7372 smokers with COPD showed that counselling combined with NRT had the greatest effect on prolonging abstinence rates versus usual care alone (odds ratio (OR) 5.08, 95\% CI 4.32-5.97; $\mathrm{p}<0.0001$ ), and versus counselling alone (OR 2.80,95\% CI 1.49-5.26; $\mathrm{p}=0.001$ ). The second most effective intervention overall was counselling combined with an antidepressant (OR 3.32, 95\% CI 1.53-7.21; $\mathrm{p}=0.002$ ) (and this seems more effective than in other smokers with presumably lower rates of depression). Counselling alone was of borderline superiority above usual care (OR 1.81, 95\% CI 0.96-3.44; p=0.07) [35].

Varenicline. Varenicline is the most recently approved medication to aid cessation [60]. In a RCT of 504 smokers with mild and moderate COPD, treatment with varenicline for 12 weeks plus cognitive behavioural therapy resulted in a week 9-52 continuous abstinence rate of 17 versus $6 \%$ in the placebo group (OR 4.04, 95\% CI 2.13-7.67) [51]. 
Systematic reviews of pharmacotherapy

In a systematic review, the average 12-month continuous abstinence rates for smokers with moderate-to-severe COPD were $1.4 \%$ for usual care, $2.6 \%$ for minimal counselling, $6.0 \%$ for intensive counselling and $12.3 \%$ for intensive counselling plus pharmacotherapy. Compared with usual care, the costs per quality-adjusted life year gained were 16900 euros for minimal counselling, 8200 euros for intensive counselling and 2400 euros for intensive counselling plus pharmacotherapy [36].

In a cohort of 472 smokers with severe or very severe COPD attending a specialist smoking cessation service in Spain who were treated with a combination of pharmacotherapy and behavioural support, $49 \%$ quit at 24 weeks (quit rates on different medications were $44 \%$ with nicotine patch, 55\% with bupropion and $61 \%$ with varenicline). 12 month quit rates were not reported [61].

\section{Smoking cessation in patients with lung cancer \\ Smoking as a cause of lung cancer}

Tobacco smoke contains over 60 known carcinogens, $85 \%$ of lung cancer cases are caused by inhaling tobacco smoke and the lifetime risk of dying of lung cancer by the age of 75 years in continuous smokers is $16 \%$ [62]. There is no threshold level of smoking under which exposure is without risk [62]. All histological subtypes of lung cancer are caused by tobacco smoke [63].

\section{Benefits of smoking cessation in patients with lung cancer}

Many studies report that smoking cessation after a diagnosis of lung cancer is associated with health improvements (table 4) [64-83].

\section{Worse surgical complications in smokers}

A retrospective cohort study showed that survival at 120 weeks following surgery for nonsmall cell lung cancer (NSCLC) in non- and ex-smokers was $60-70 \%$ compared with only $25 \%$ in continuing smokers [64]. There are many biological explanations for this difference including increased complications from treatment, recurrences and new incidental tumours. Data from the American Society of Thoracic Surgeons on 7990 patients undergoing primary resection of NSCLC between 1999 and 2007 showed that hospital mortality and the risk of pulmonary complications were lower not only in never or long-term ex-smokers but also in those who had stopped smoking as recently as 1-12 months before surgery [65]. These retrospective data are prone to reporting bias (especially as smoking was usually self-reported) and quitting may be a marker for other prognostic factors such as higher socioeconomic group, more compliance with medications, etc. However, a meta-analysis of RCTs in non-lung cancer surgery showed statistically significant benefits of preoperative smoking intervention on total complication rates, surgical wound complications, cardiovascular complications, re-operations and a shorter hospital stay, but individual studies (often elective procedures) were not powered for survival [66]. Earlier smoking cessation is better, with each week of cessation lowering the risk of post-operative complications by $19 \%$. Trials of at least 4 weeks of cessation showed significantly larger effects than shorter trials [67]. Another systematic review included less well designed studies and was, therefore, reluctant to draw firm conclusions [68].

TABLE 4 Benefits of smoking cessation in lung cancer

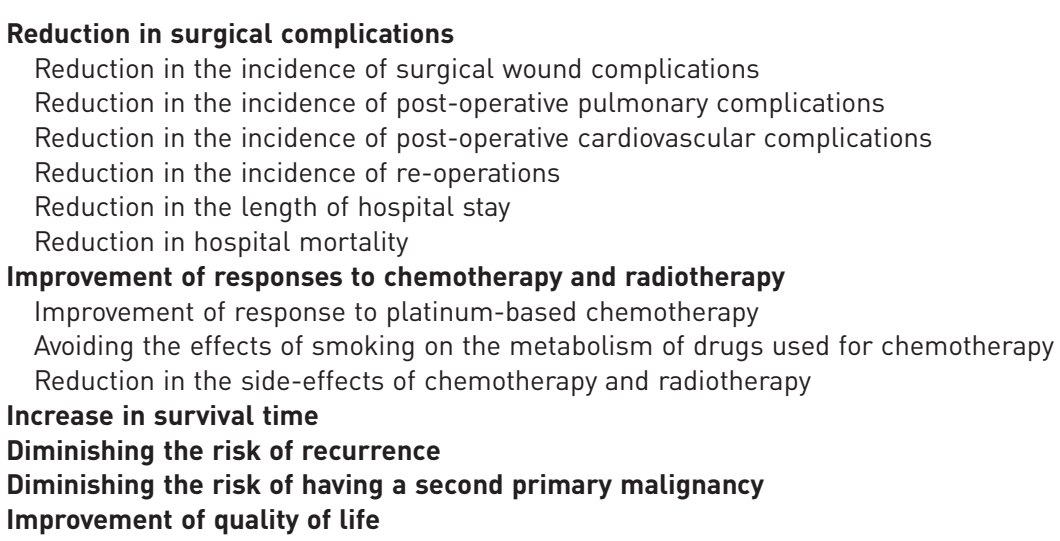


Worse response to chemotherapy in smokers

A retrospective study of 285 patients (63\% current smokers) receiving platinum-based chemotherapy for lung cancer found nonresponders $(n=191)$ to have smoked significantly more than responders $(67.8 \pm 35.1$ versus $38.7 \pm 27.1$ pack-years; $\mathrm{p}<0.001)$. Multivariate analysis confirmed that heavy tobacco consumption ( $\geq 40$ pack-years) was the most important independent negative predictor of response (adjusted OR 10.4, 95\% CI 5.1-21.3) [69]. A small study in Asian patients yielded similar results [70].

Smoking affects drug metabolism. The epidermal growth factor receptor (EGFR) inhibitor, erlotinib is metabolised to a greater extent in smokers due to induction of the cytochrome P450 enzyme, CYP1A1/1A2 [71]. In a phase I/II study, the maximum tolerated daily dose was double (300 mg) in smokers, despite similar incidence of skin toxicity and diarrhoea, suggesting faster metabolism [72]. The dose-normalised area under the plasma concentration-time curve of irinotecan was significantly lower in smokers than nonsmokers, indicating an increased risk for treatment failure [69, 73, 74]. Smokers with NSCLC have fewer activating EGFR mutations $[75,76]$ and anaplastic lymphoma kinase positive driver gene alterations reducing the chances of responding to these inhibitors $[74,76]$.

Worse response to radiotherapy in smokers

In 83 patients receiving curative radiotherapy for NSCLC, smoking was an independent risk factor for developing radiation pneumonitis [77] and pulmonary infections [76]. Median and two-year survival rates were also longer in nonsmokers [79].

Worse survival time and increased risk of recurrence or second primary lung malignancy in smokers In 215 patients with limited-disease small cell lung cancer (SCLC) treated with radio-chemotherapy, patients who quit smoking during therapy had a median survival time of 18.0 months versus 13.6 months for those who continued to smoke. The five-year survival rate for the two groups (8.9 versus $4.0 \%$, respectively; $\mathrm{p}=0.0017$ ) suggested smoking cessation before radio-chemotherapy was associated with improved long-term outcome, but whether this was a direct cause or merely a marker of other prognosticators is not known [80].

A meta-analysis of 10 RCTs and observational studies showed continued smoking was associated with a significantly increased risk of all-cause mortality (hazard ratio (HR) 2.94, 95\% CI 1.15-7.54) and recurrence (HR 1.86, 95\% CI 1.01-3.41) in early stage NSCLC and of all-cause mortality (HR 1.86, 95\% CI 1.33-2.59), development of a second primary tumour (HR 4.31,95\% CI 1.09-16.98), and recurrence (HR 0.26, 95\% CI 1.06-1.50) in limited stage SCLC. Life table modelling estimated the 5 year survival in 65 year-old patients with early NSCLC who continued smoking to be $33 \%$, compared with $70 \%$ for those who quit smoking. In limited stage SCLC, an estimated $29 \%$ of continuing smokers would survive for 5 years compared with $63 \%$ of quitters [81].

Improvement in quality of life after quitting in smokers with lung cancer

Quality of life and performance status improve in lung cancer after quitting smoking [82]. In 70 consecutive patients undergoing lobectomy or pneumonectomy for NSCLC, smoking at the time of surgery was associated with a poorer post-operative quality of life score. Cessation was associated with improved quality of life scores at any time point relative to lung cancer surgery [83].

A cohort study of over 1500 patients found that never- and former-smokers with lung cancer had a better tumour-specific quality of life score than smokers [84]. Smoking cessation in 200 people with NSCLC was associated with better performance status and quality of life [82].

\section{Characteristics of smokers with lung cancer}

Willingness to quit is particularly high immediately after a diagnosis of lung cancer is discussed with smokers. The importance of this "teachable moment" is reported in two large lung cancer screening trials $[85,86]$. Despite high levels of nicotine dependence [85], smoking cessation rates in general cancer patients [87] and lung cancer patients [88] are comparable with "healthy" controls. For example, 40-53\% of lung, and head and neck cancer patients were abstinent 6 months following treatment $[89,90]$.

\section{Characteristics of lung cancer patients who continue to smoke}

$\sim 10-13 \%$ of people still smoke 6 months following a diagnosis of lung cancer [88-90]. Younger age, depression, and having a household member who smokes are factors that are associated with not quitting [91]. Smoking cessation treatments for patients with lung cancer are similar to those for patients with COPD and follow-up is often tied to other treatment visits and specific counselling designed to increase self-efficacy, and to reduce fatalistic thinking and emotional distress. 
TABLE 5 Characteristics of counselling for smoking cessation in smokers with lung cancer

Direct, sensible and empathic

Provided at every visit

Considers that lung cancer patients can be depressed, antidepressants are sometimes used

Considers that lung cancer patients can suffer from a high degree of nicotine dependence

The use of pharmacological treatment for smoking cessation is standard practice

Sending positive messages to patients (see table 4)

Addressing fatalistic beliefs (see table 4)

\section{Therapeutic interventions in smokers with lung cancer}

From the above evidence, healthcare professionals are aware that cessation is associated with longer survival and improved quality of life for smokers with lung cancer and they are usually alert to specific barriers to quitting.

\section{Counselling}

Whilst research into modified approaches for smokers with lung cancer continues, most Task Force members offer basic, short, directed advice:

"One of the best things you can do to fight your lung cancer is to stop smoking. I can help you to stop smoking."

Follow-up visits often coincide with other oncology visits, if possible, to reduce the onus on patients and specific information regarding treatment complications and survival benefits is supplied. Reducing fatalistic beliefs and addressing depression might also improve self-efficacy and self-esteem, especially if patients feel they have some control to contribute to one aspect of their forthcoming (often rigorous) treatments (table 5) [92].

\section{Pharmacological interventions}

NRT, bupropion, and varenicline have all been used in smokers with lung cancer. There are no RCTs of bupropion in smokers with lung cancer compared with other groups [93]. A small pilot combining varenicline with smoking cessation counselling in patients with a diagnosed or suspected thoracic malignancy showed only half of 32 eligible participants completed the 12-week course, but biochemically validated 7-day, point prevalence abstinence rates were 34.4 versus $14.3 \%$ in the control group (OR 3.14, 95\% CI 0.6-16.6; $\mathrm{p}=0.18$ ). The authors concluded the programme was feasible, acceptable and probably effective as the lack of statistical significance was probably due to the very small sample size [94].

Table 6 shows the most relevant information from this section.

\section{Smoking cessation in smokers with asthma}

The prevalence of smoking among people with asthma is similar to the general population, i.e. 20-25\% [95, 96].

\section{Benefits of smoking cessation in asthma}

Continued smoking has detrimental effects on asthma. One population based, longitudinal study over 15 years reported that smokers with asthma had a greater decline in FEV1 than nonsmokers with asthma [97]. A meta-analysis of 10 controlled trials in people with asthma using ICS showed that smokers had a reduced benefit and an increased need for concomitant medications compared with nonsmokers [98]. A Canadian study of 893 persons with asthma found that smokers had poorer asthma control, made greater use of acute care and had higher absenteeism from work or school compared with their nonsmoking

\section{TABLE 6 Summary of the relevant issues for smoking cessation in patients with lung cancer}

$85 \%$ of lung cancer cases are caused by smoking

Smoking cessation after a diagnosis of lung cancer is associated with health improvements

Being diagnosed as having lung cancer is a "teachable moment" for smoking cessation

10-13\% of lung cancer patients still smoke 6 months after diagnosis

Smoking cessation strategies for lung cancer patients include: counselling (see table 5) and use of pharmacological treatment (nicotine replacement therapy, bupropion and varenicline) 
counterparts [99]. Stopping smoking is followed by better asthma control. One study found that after several weeks of quitting persons with asthma showed improved pulmonary function and a reduction in neutrophils in their sputum [100].

\section{Smoking characteristics in patients with asthma}

Analysis of 195057 calls to quit-lines in 15 states in the USA from 2005 to 2008 showed that callers with asthma were less likely to quit compared with those without disease after a 7 month follow-up period [101]. Smokers with asthma are less likely to use appropriate methods to manage their asthma and are less likely to attend asthma education programmes compared with nonsmokers [102]. Some studies report that smokers with asthma develop nicotine dependence more quickly than smokers without asthma, which could explain fewer successful quit attempts [103].

\section{Therapeutic interventions in patients with asthma}

There are few studies of smoking cessation in patients with asthma. In an observational study of ever-smokers with asthma, the median time until quitting was 17 years [104]. A small interventional study of 32 smokers with asthma found $66 \%$ quit at 6 weeks but the longer term success was not reported [100]. A study of 57 smokers with asthma treated with NRT, bupropion and counselling found a 12-month quit rate of $28 \%$ [105].

The only RCT of smoking cessation in people with asthma randomised 220 smokers to: 1) smoking reduction (reducers); 2) complete smoking cessation (abstainers); or 3) continuation of usual smoking (continuing smokers). Subjects used nicotine chewing gum or an oral nicotine inhaler to promote reduction and cessation [106]. Cessation rates were $15 \%$ in both the cessation and reduction groups versus $3 \%$ in the control group. Asthma control and bronchial reactivity improved in quitters, but to a lesser extent in reducers [106].

Standard doses and duration of licensed pharmacotherapies with counselling are recommended [105, 106], but in clinical guidelines for treatment of asthma the importance of cessation is only briefly mentioned alongside the lack of smoking cessation trials specifically for asthma patients $[107,108]$.

The percentage of smokers with asthma that quit smoking can be used as a quality indicator for asthma clinics. As smokers with asthma may be several decades younger than smokers with COPD, cessation benefits will be larger in terms of quality-adjusted life years gained and so probably more cost-effective.

Table 7 shows a brief summary of the relevant issues from this section.

\section{Smoking cessation in patients with pulmonary TB}

TB remains a global emergency killing 1.4 million people every year [109]. As smoking prevalence has risen in developing countries [110] more people with TB smoke now than ever [111].

\section{Smoking prevalence in patients with TB}

Smoking is more prevalent in people with TB compared with people without TB [112-123], with the risk of TB increasing in people who smoke more and who have smoked for more years. Meta-analyses suggest that smoking is an important risk factor for both pulmonary and extrapulmonary TB [124-126]. Moreover, TB is one of the "new" illnesses causally linked to smoking in the 2014 update of the US Surgeon General's Report [62].

\section{Passive smoking and TB}

A community survey of 1344 people showed that children who lived in a household with a patient with $\mathrm{TB}$, were significantly and independently at increased risk of TB infection if they were exposed to passive

\footnotetext{
TABLE 7 Summary of the relevant issues for smoking cessation in patients with asthma

Smoking rate among asthma patients is similar to the general population

Smoking has detrimental effects on asthma

Greater decline in forced expiratory volume in $1 \mathrm{~s}$

Lack of response to medications (bronchodilator drugs and inhaled corticosteroids)

Increased need for use of concomitant medications

Asthma patients who smoke can suffer from higher nicotine dependence and are less likely to attend education programmes

Counselling and use of pharmacological treatments is a good approach for smoking cessation in asthma patients; nevertheless, there is a lack of smoking cessation trials in these patients
} 
smoking than if there was no added smoke in the house [127]. Cohort studies confirm this [128], with TB risk increasing with more tobacco smoke exposure $[124,129]$.

\section{Effects of smoking on TB course and treatment}

Longitudinal studies worldwide associate current smoking with worse TB outcome; it independently predicts positivity for acid-fast bacilli, delayed sputum conversion to negative cultures, longer duration of symptoms before diagnosis, prolonged infectivity, worse radiographic changes at presentation and longer time to recovery [130], chronic dyspnoea and fibrosis [131], and TB treatment failure and more deaths $[120,121,131-138]$.

\section{Mechanisms of how continued smoking leads to worse TB outcomes \\ Smoker's behaviour}

Smokers with TB may present later because they interpret worsening cough or breathless as due to their smoking or delay seeking help because they do not want healthcare professionals to judge or address their smoking [121]. Smokers have been shown to be less compliant with TB medications than nonsmokers [139].

\section{Biological mechanisms}

Current smokers had a lower body mass index when diagnosed with TB [140] probably reflecting more advanced disease (see earlier), and certainly less physiological reserve. Nicotine reduces production of tumour necrosis factor- $\alpha$ by alveolar macrophages [126] rendering the patient more susceptible to progressive disease from latent infection. Tobacco smoke also reduces mucociliary clearance and the immune activity of a variety of cells [141].

\section{Drug metabolism}

Smokers show increased clearance of antimicrobial metabolites through induction of the cytochrome P450 enzymes. Serum rifampicin levels were lower in smokers compared with nonsmokers [142].

\section{Smoking cessation in patients with TB}

In a study from rural China, 55\% of smokers reported stopping after a TB diagnosis but nearly one-fifth relapsed within 15 months [119]. Similar findings were reported from India [143] and Indonesia [144].

\section{Barriers to smoking cessation in patients with TB}

Focus group work suggests that patients diagnosed with TB were more receptive to advice to quit, but that they might start smoking again after recovery and some quit attempts were inhibited by exposure to smoking at TB facilities despite the presence of a "teachable moment" [145]. Healthcare professionals dealing with TB in developing nations sometimes advise patients with TB about smoking less $[143,144]$ and in one study only $5 \%$ believed they were sufficiently trained in smoking cessation techniques [146]. Furthermore, smoking cessation pharmacotherapy is less available and relatively expensive for use on a large scale in developing countries.

\section{Benefits of quitting smoking and quit strategies in patients with TB}

Training TB healthcare workers using DOTS (directly observed treatment, short-course) in Rio de Janeiro, Brazil to deliver smoking cessation for 1 day improved their self-rated efficacy but the effects on smoking rates were not reported [147].

SIDDIQI et al. [148] performed a cluster RCT in 1955 adult smokers with suspected TB in Pakistan. Validated continuous smoking abstinence rates at 1 and 6 months were significantly higher with behavioural cessation support alone $(41 \%)$ or with support combined with bupropion therapy (45\%) compared with usual care (8.5\%) [148]. Smokers with TB had greater improvements in quality of life over 6 months, when assigned to DOTS plus cessation support compared with DOTs alone [149].

Healthcare professionals provide a brief behavioural cessation intervention at diagnosis followed by monthly behavioural support throughout the TB treatment course and pharmacotherapy is offered wherever possible. The intervention and (self-reported) quit attempts may be recorded, e.g. on a modified TB treatment card [150].

Table 8 summarises the most relevant issues from this section.

\section{Smoking cessation in smokers that find it difficult to quit}

This section describes the therapeutic approach for smokers who are fully aware of the health risks and benefits of stopping smoking and who would like to become nonsmokers, but cannot overcome the barriers to quitting (loss of reward, withdrawal, discomfort, stress, weight gain, etc.).

These smokers are often offered a combination of counselling and pharmacological treatment. For those who have already received standard support and pharmacotherapy many Task Force members have found 
TABLE 8 Summary of the relevant issues for smoking cessation in patients with tuberculosis (TB)

Smoking rate among people with TB is higher than in the general population

Smoking is an important risk factor for both pulmonary and extrapulmonary TB

TB risk increases in those exposed to passive smoking

Smoking leads to worse TB outcomes

Smokers present later to healthcare providers

Smokers are less compliant with TB medications

Smoking alters immunological responses and reduces mucociliary clearance

Smoking increases clearance of TB medications

Smoking cessation strategies for TB patients include: a combination of counselling (brief behavioural intervention at diagnosis followed by monthly behavioural support throughout the TB treatment course) and pharmacological treatment (nicotine replacement therapy, bupropion and varenicline)

it helpful to change the style of the advice as well as its content. Being empathic, being understanding, and showing respect towards the patients' opinions regarding their smoking can make patients interested and attentive again [151]. Advice often focuses on reducing smoking rather than quitting abruptly. There are two possible benefits of smoking reduction. Most importantly, it can be a way to gradually achieve stopping smoking altogether [152]. The other possible benefit is to reduce the harm from smoking where complete cessation is not achieved. Although there is a strong relationship between cigarette consumption and the disease-risk, the reduction of risk associated with reduced smoking is not as clear. This is because unaided reduction may be accompanied by more vigorous puffing on the remaining cigarettes. For such a reduction to generate amelioration of risk or symptoms it probably has to be substantial (at least by $50 \%$ ) and for an extended period of time [106, 153].

Three specific behavioural procedures have been proposed to aid smoking reduction by HuGHES et al. [154]: 1) creating a hierarchy of the importance of each cigarette throughout an average day and start omitting those cigarettes either from the top (most needed) or from the bottom (least needed); 2) increasing the time interval between cigarettes; and 3) counting the number of cigarettes per day and making sure the number is within the quota allowed. The efficacy of these three alternatives appears uncertain and similar [154].

Both harm reduction and complete cessation using pharmacological support are much more promising. Standard doses of NRT [56, 152, 155] and varenicline [156] have helped reduction to quit (more than placebo), but bupropion doesn't seem as effective [155]. Different classes of pharmacotherapy are increasingly prescribed (off licence) in combination, in higher doses and for longer periods than normally recommended for those with particularly high addiction and/or ongoing withdrawal symptoms. Treatment with nicotine patches for 2 weeks prior to a predetermined quit date has also improved success for smokers who failed previous attempts to quit with NRT at standard doses [157-159]. For smokers who have failed in a previous attempt with varenicline, treatment may be prolonged for 24 weeks [155] or it may be started 4 weeks prior to the target quit date [160] to improve quit rates. A recent randomised clinical study has shown that the combination of varenicline with nicotine patches is more effective than varenicline alone [161], although a previous study did not show this [162]. Another study showed that the combination of varenicline with bupropion was more effective than varenicline alone at 6 months but not at 1 year of follow-up [163].

Figure 2 provides the reader with a therapeutic approach for smokers that find it difficult to quit.

\section{Conclusions}

1) Like anyone else, smokers with COPD, lung cancer, asthma and TB are always advised to stop smoking. Healthcare professionals always make it clear that quitting smoking is the best thing these patients can do to improve their lung health. Smokers are usually offered a combination of counselling and pharmacological treatments.

2) Many patients remain unable to stop despite being aware of the specific link between their condition and smoking, and having a desire to stop. This suggests that they are highly dependent. They may face other barriers to successful smoking cessation compared with other smokers.

3) Using smoking cessation medications has been shown to be useful. NRT, bupropion and varenicline all have strong evidence of efficacy. A combination of two or more NRT products, higher than usual dosing, extended use prior to quitting and extended use post-quitting can improve treatment efficacy. Extended use of varenicline prior to and after the target quit date, and the combination of varenicline with nicotine patches or bupropion can improve treatment outcomes. 


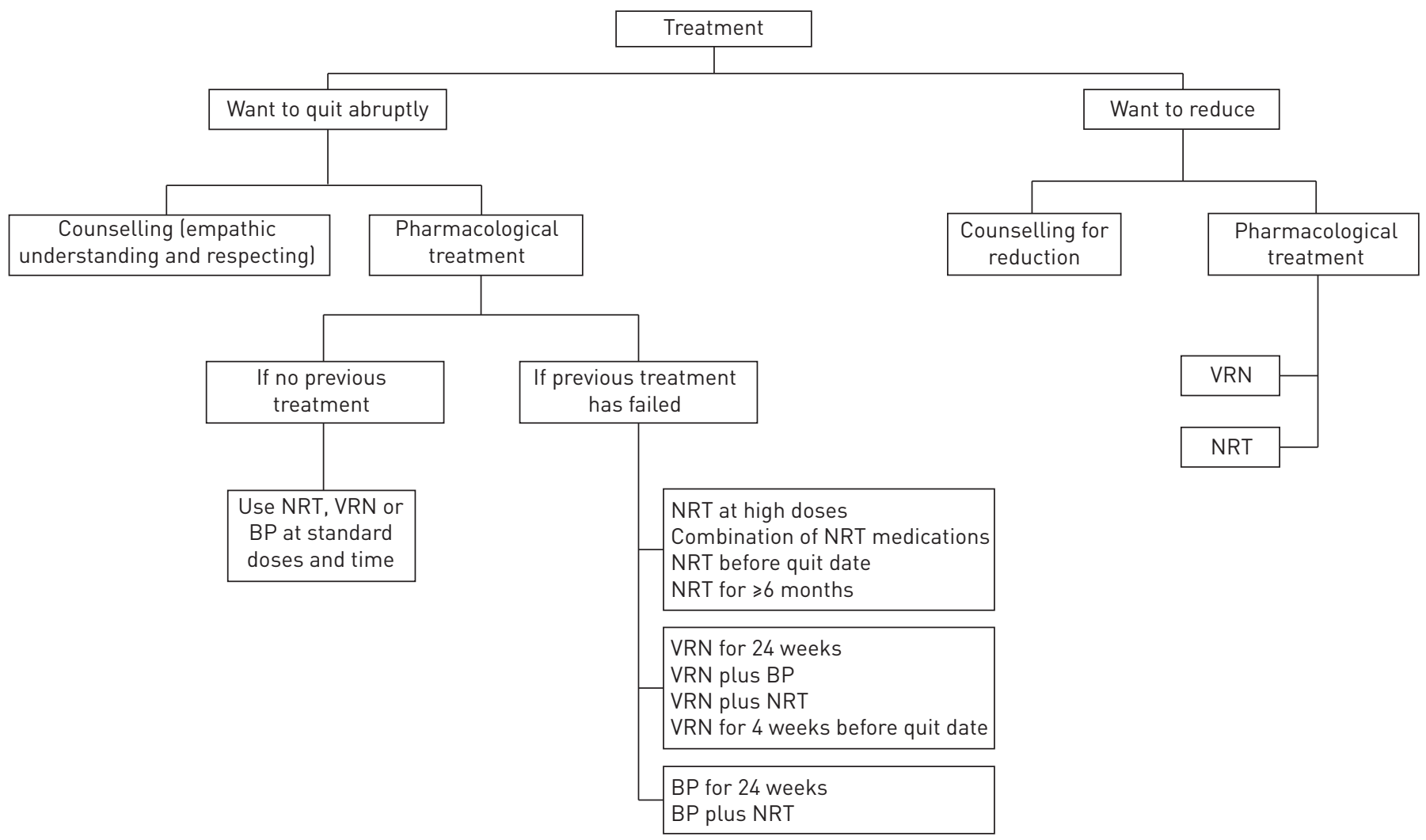

FIGURE 2 The therapeutic approach used by most Task Force members for smokers that find it difficult to quit. NRT: nicotine replacement therapy; VRN: varenicline; BP: bupropion.

4) In smokers who are highly motivated to quit but are unable to do so, a harm reduction approach is often considered using varenicline and NRT at higher doses and for a more prolonged duration prior to quitting. In some patients, at least, such intervention can still facilitate successful cessation.

\section{References}

1 Tønnessen P, Paoletti P, Gustavsson G, et al. Higher dosage nicotine patches increase one-year smoking cessation rates: results from the European CEASE-trial. Eur Respir 1999; 13: 238-246.

2 Tønnesen P, Carrozzi L, Fagerström KO, et al. Smoking cessation in patients with respiratory diseases: a high priority, integral component of therapy. Eur Respir J 2007; 29: 390-417.

3 SmokeHaz: a scientific review of the health hazards of smoking. www.europeanlung.org/en/projects-and-research/ projects/smokehaz/home Date last accessed: December 13, 2014.

4 Chapman KR, Mannino DM, Soriano JB, et al. Epidemiology and costs of chronic obstructive pulmonary disease. Eur Respir J 2006; 27: 188-207.

5 Miller A, Raskin J. The natural history of COPD: confirming and going beyond Fletcher and Peto. Eur Respir J 2014; 44: 280-283.

6 Fletcher C, Peto R. The natural history of chronic airflow obstruction. Br Med J 1977; 1: 1645-1648.

7 Kerstjens HA, Rijcken B, Schouten JP, et al. Decline of FEV1 by age and smoking status: facts, figures, and fallacies. Thorax 1997; 52: 820-827.

8 Gold DR, Wang X, Wypij D, et al. Effects of cigarette smoking on lung function in adolescent boys and girls. N Engl J Med 1996; 335: 931-937.

9 Sherrill DL, Lebowitz MD, Knudson RJ, et al. Smoking and symptom effects on the curves of lung function growth and decline. Am Rev Respir Dis 1991; 144: 17-22.

10 Anthonisen NR, Connett JE, Murray RP. Smoking and lung function of Lung Health Study participants after 11 years. Am J Respir Crit Care Med 2002; 166: 675-679.

11 Anthonisen NR, Skeans MA, Wise RA, et al. The effects of a smoking cessation intervention on 14.5-year mortality: a randomized clinical trial. Ann Intern Med 2005; 142: 233-239.

12 Global Strategy for the Diagnosis, Management and Prevention of COPD. Global Initiative for Chronic Obstructive Lung Disease (GOLD), 2010. www.goldcopd.org Date last accessed: August 20, 2014. Date last updated: January, 2015.

13 Kohansal R, Martinez-Camblor P, Agustí A, et al. The natural history of chronic airflow obstruction revisited: an analysis of the Framingham offspring cohort. Am J Respir Crit Care Med 2009; 180: 3-10.

14 Scanlon PD, Connett JE, Waller LA, et al. Smoking cessation and lung function in mild-to-moderate chronic obstructive pulmonary disease. The Lung Health Study. Am J Respir Crit Care Med 2000; 161: 381-390.

15 van Schayck OC, Haughney J, Aubier M, et al. Do asthmatic smokers benefit as much as non-smokers on budesonide/ formoterol maintenance and reliever therapy? Results of an open label study. Respir Med 2012; 106: 189-196. 
16 Vogelmeier C, Hederer B, Glaab T, et al. Tiotropium versus salmeterol for the prevention of exacerbations of COPD. N Engl J Med 2011; 364: 1093-1103.

17 Jiménez-Ruiz CA, Masa F, Miravitlles $\mathrm{M}$, et al. Smoking characteristics: differences in attitudes and dependence between healthy smokers and smokers with COPD. Chest 2001; 119: 1365-1370.

18 Shahab L, Jarvis MJ, Britton J, et al. Prevalence, diagnosis and relation to tobacco dependence of chronic obstructive pulmonary disease in a nationally representative population sample. Thorax 2006; 61: 1043-1047.

19 Jiménez-Ruiz CA, Miravitlles M, Sobradillo V, et al. Can cumulative tobacco consumption, FTND score, and carbon monoxide concentrations in expired air be predictors of chronic obstructive pulmonary disease? Nicotine Tob Res 2004; 6: 649-653.

20 Crowley TJ, Macdonald MJ, Walter MI. Behavioural anti-smoking trial in chronic obstructive pulmonary disease patients. Psychopharmacology 1995; 119: 193-204.

21 Wagena EJ, Arrindell WA, Wouters EF, et al. Are patients with COPD psychologically distressed? Eur Respir J 2005; 26: 242-248

22 Postma DS, Siafakas NM, eds. Management of Chronic Obstructive Pulmonary Disease. ERS Monogr 1998; 7.

23 Javors MA, Hatch JP, Lamb RJ. Cut-off levels for breath carbon monoxide as a marker for cigarette smoking. Addiction 2005; 100: 159-167.

24 Simmons VN, Litvin EB, Jacobsen PB, et al. Predictors of smoking relapse in patients with thoracic cancer or head and neck cancer. Cancer 2011; 119: 1420-1427.

25 Rollnick S, Mason P, Butler C, et al. Health Behaviour Change: A Guide for Practitioners. London, Churchill Livingstone, 1999.

26 Heatherton TF, Kozlowski LT, Frecker RC, et al. The Fagerström test for nicotine dependence: a revision of the Fagerström tolerance questionnaire. Br J Addict 1991; 86: 1119-1127.

27 World Health Organization. The ICD-10 Classification of Mental and Behavioural Disorders. Geneva, World Health Organization, 1992.

28 Etter JF, Le Houezec J, Perneger TV. A self-administered questionnaire to measure addiction to cigarettes: the cigarette dependence scale. Neuropsychopharmacology 2003; 28: 359-370.

29 Vangeli E, Stapleton J, Smit ES, et al. Predictors of attempts to stop smoking and their success in adult general population samples: a systematic review. Addiction 2011; 106: 2110-2121.

30 Pomerleau OF, Fagerström KO, Marks J, et al. Development and validation of a self-rating scale for positive- and negative-reinforcement smoking: the Michigan Nicotine Reinforcement Questionnaire. Nicotine Tob Res 2003; 5: 711-718.

31 Snedecor S, Pomerleau CS, Pomerleau OF, et al. POS2-118 A confirmatory factor analysis and concurrent validation of the Michigan Nicotine Reinforcement Questionnaire. 12th annual meeting of the Society for Research on Nicotine and Tobacco, Orlando, FL. 2006. https://srnt.org/conferences/abstracts/pdfs/2006_Abstracts.pdf

32 Jimenez Ruiz CA, Cicero Guerrero AM, Mayayo Ulibarri ML, et al. Phenotypic features in COPD smokers attending a smoking cessation unit. Eur Respir J 2011; 38: p1562.

33 Fagerström KO. Time to first cigarette: the best single indicator of tobacco dependence? Monaldi Arch Chest Dis 2003; 59: 91-94.

34 Arrol B, Khin N, Kerse N. Screening for depression in primary care with two verbally asked questions: cross-sectional study. BMJ 2003; 327: 1144-1146.

35 Strassmann R, Bausch B, Spaar A, et al. Smoking cessation interventions in COPD: a network meta-analysis of randomised trials. Eur Respir J 2009; 34: 634-640.

36 Hoogendoorn M, Feenstra TL, Hoogenveen RT, et al. Long-term effectiveness and cost-effectiveness of smoking cessation interventions in patients with COPD. Thorax 2010; 65: 711-718.

37 Thabane M; COPD Working Group. Smoking cessation for patients with chronic obstructive pulmonary disease (COPD): an evidence-based analysis. Ont Health Technol Assess 2012; 12: 1-50.

38 van der Meer RM, Wagena EJ, Ostelo RW, et al. Smoking cessation for chronic obstructive pulmonary disease. Cochrane Database Syst Rev 2003; 2: CD002999.

39 Andreas S, Batra A, Behr J, et al. Tabakentwöhnung bei COPD [Smoking cessation in patients with COPD]. Pneumologie 2014; 68: 237-258.

40 Kanner RE, Connett JE, Williams DE, et al. Effects of randomized assignment to a smoking cessation intervention and changes in smoking habits on respiratory symptoms in smokers with early chronic obstructive pulmonary disease: the Lung Health Study. Am J Med 1999; 106: 410-416.

41 Brandt CJ, Ellegaard H, Joensen MB, et al. Effects of diagnosis of "smoker's lung". Lancet 1997; 349: 253.

42 Kotz D, Huibers MJ, West RJ, et al. What mediates the effect of confrontational counselling on smoking cessation in smokers with COPD? Patient Educ Couns 2009; 76: 16-24.

43 Sundblad BM, Larsson K, Nathell L. Lung function testing influences the attitude toward smoking cessation. Nicotine Tob Res 2010; 12: 37-42.

44 Bize R, Burnand B, Mueller Y, et al. Biomedical risk assessment as an aid for smoking cessation. Cochrane Database Syst Rev 2009; 2: CD004705.

45 Parkes G, Greenhalgh T, Griffin M, et al. Effect on smoking quit rate of telling patients their lung age: the Step2quit randomised controlled trial. BMJ 2008; 336: 598-600.

46 Lacasse Y, LaForge J, Maltais F. Got a match? Home oxygen therapy in current smokers. Thorax 2006; 61: 374-375.

47 Tønnesen P, Mikkelsen K, Bremann L. Nurse-conducted smoking cessation in patients with COPD using nicotine sublingual tablets and behavioral support. Chest 2006; 130: 334-342.

48 Tashkin DP, Kanner R, Bailey W, et al. Smoking cessation in patients with chronic obstructive pulmonary disease: a double-blind, placebo-controlled, randomised trial. Lancet 2001; 357: 1571-1575.

49 Wagena EJ, Knispchild PG, Huibers MJ, et al. Efficacy of bupropion and nortryptiline for smoking cessation among people at risk for or with chronic obstructive pulmonary disease. Arch Intern Med 2005; 165: 2286-2292.

50 Van Schayck CP, Kaper J, Wagena EJ, et al. The cost-effectiveness of antidepressants for smoking cessation in chronic obstructive pulmonary disease (COPD) patients. Addiction 2009; 104: 2110-2117.

51 Tashkin DP, Rennard S, Hays JT, et al. Effects of varenicline on smoking cessation in patients with mild to moderate COPD: a randomized controlled trial. Chest 2011; 139: 591-599. 

anticholinergic bronchodilator on the rate of decline of FEV1. The Lung Health Study. JAMA 1994; 272 : 1497-1505.

53 Tønnesen P, Mikkelsen KL. Smoking cessation with four nicotine regimes in a lung clinic. Eur Respir J 2000; 16: 717-722.

54 Silagy C, Lancaster T, Stead L, et al. Nicotine replacement therapy for smoking cessation. Cochrane Database Syst Rev 2004; 3: CD000146.

55 Sundblad BM, Larsson K, Nathell L. High rates of smoking abstinence in COPD patients: smoking cessation by hospitalization. Nicotine Tob Res 2008; 10: 883-890.

56 Moore D, Aveyard P, Connock M, et al. Effectiveness and safety of nicotine replacement therapy assisted reduction to stop smoking: systematic review and meta-analysis. BMJ 2009; 338: b1024.

57 Pisinger C, Godtfredsen NS. Is there a health benefit of reduced tobacco consumption? A systematic review. Nicotine Tob Res 2007; 9: 631-646.

58 Kanner RE, Anthonisen NR, Connett JE, et al. Lower respiratory illnesses promote FEV1 decline in current smokers but not ex-smokers with mild chronic obstructive pulmonary disease: results from the lung health study. Am J Respir Crit Care Med 2001; 164: 358-364.

59 Simmons MS, Connett JE, Nides NA, et al. Smoking reduction and the rate of decline in FEV 1 : results from the Lung Health Study. Eur Respir J 2005; 25: 1011-1017.

60 Zierler-Brown SL, Kyle JA. Oral varenicline for smoking cessation. Ann Pharmacother 2007; 41: 95-99.

61 Jiménez-Ruiz CA, Ramos Pinedo A, Cicero Guerrero A, et al. Characteristics of COPD smokers and effectiveness and safety of smoking cessation medications. Nicotine Tob Res 2012; 14: 1035-1039.

62 U.S. Department of Health and Human Services. The health consequences of smoking - 50 years of progress: a report of the Surgeon General, 2014. Atlanta, U.S. Department of Health and Human Services, Centers for Disease Control and Prevention, National Center for Chronic Disease Prevention and Health Promotion, Office on Smoking and Health, 2014. www.surgeongeneral.gov/library/reports/50-years-of-progress Date last accessed: August 20, 2014.

63 Pesch B, Kendzia B, Gustavsson P, et al. Cigarette smoking and lung cancer - relative risk estimates for the major histological types from a pooled analysis of case-control studies. Int J Cancer 2012; 131: 1210-1219.

64 Sardari Nia P, Weyler J, Colpaert C, et al. Prognostic value of smoking status in operated non-small cell lung cancer. Lung Cancer 2005; 47: 351-359.

65 Mason DP, Subramanian S, Nowicki ER, et al. Impact of smoking cessation before resection of lung cancer: a society of thoracic surgeons general thoracic surgery database study. Ann Thorac Surg 2009; 88: 362-370.

66 Møller AM, Villebro N, Pedersen T, et al. Effect of preoperative smoking intervention on postoperative complications: a randomised clinical trial. Lancet 2002; 359: 114-117.

67 Mills E, Eyawo O, Lockhart I, et al. Smoking cessation reduces postoperative complications: a systematic review and meta-analysis. Am J Med 2011; 124: 144-154.

68 Schmidt-Hansen M, Page R, Hasler E. The effect of preoperative smoking cessation or preoperative pulmonary rehabilitation on outcomes after lung cancer surgery: a systematic review. Clin Lung Cancer 2013; 14: 96-102.

69 Duarte RL, Luiz RR, Paschoal ME. The cigarette burden (measured by the number of pack-years smoked) negatively impacts the response rate to platinum-based chemotherapy in lung cancer patients. Lung Cancer 2008; 61: 244-254.

70 Mohan A, Singh P, Kumar S, et al. Effect of change in symptoms, respiratory status, nutritional profile and quality of life on response to treatment for advanced non-small cell lung cancer. Asian Pac J Cancer Prev 2008; 9: 557-562.

71 Shepherd FA, Rodrigues Pereira J, Ciuleanu T, et al. Erlotinib in previously treated non-small-cell lung cancer. $N$ Engl J Med 2005; 353: 123-132.

72 Hughes AN, O’Brien ME, Petty WJ, et al. Overcoming cypla1/1a2 mediated induction of metabolism by escalating erlotinib dose in current smokers. J Clin Oncol 2009; 27: 1220-1226.

73 van der Bol JM, Mathijssen RH, Loos WJ, et al. Cigarette smoking and irinotecan treatment: pharmacokinetic interaction and effects on neutropenia. J Clin Oncol 2007; 25: 2719-2726.

74 Couraud S, Zalcman G, Milleron B, et al. Lung cancer in never smokers - a review. Eur J Cancer 2012; 48: 1299-1311.

75 Lee YJ, Cho BC, Jee $\mathrm{SH}$, et al. Impact of environmental tobacco smoke on the incidence of mutations in epidermal growth factor receptor gene in never-smoker patients with non-small-cell lung cancer. J Clin Oncol 2009; 28: 487-492.

76 An SJ, Chen ZH, Su J, et al. Identification of enriched driver gene alterations in subgroups of non-small cell lung cancer patients based on histology and smoking status. PLoS One 2012; 7: e40109.

77 Monson JM, Stark P, Reilly JJ, et al. Clinical radiation pneumonitis and radiographic changes after thoracic radiation therapy for lung carcinoma. Cancer 1998; 82: 842-850.

78 Sarihan S, Ercan I, Saran A, et al. Evaluation of infections in non-small cell lung cancer patients treated with radiotherapy. Cancer Detect Prev 2005; 29: 181-188.

79 Fox JL, Rosenzweig KE, Ostroff JS. The effect of smoking status on survival following radiation therapy for non-small cell lung cancer. Lung Cancer 2004; 44: 287-293.

80 Videtic GM, Stitt LW, Dar AR, et al. Continued cigarette smoking by patients receiving concurrent chemoradiotherapy for limited-stage small-cell lung cancer is associated with decreased survival. J Clin Oncol 2003; 21: 1544-1549.

81 Parsons A, Daley A, Begh R, et al. Influence of smoking cessation after diagnosis of early stage lung cancer on prognosis: systematic review of observational studies with meta-analysis. BMJ 2010; 340: b5569.

82 Chen J, Qi Y, Wampfler JA, et al. Effect of cigarette smoking on quality of life in small cell lung cancer patients. Eur J Cancer 2012; 48: 1593-1601.

83 Balduyck B, Sardari Nia P, Cogen A, et al. The effect of smoking cessation on quality of life after lung cancer surgery. Eur J Cardiothorac Surg 2012; 40: 1432-1437.

84 Garces YI, Yang P, Parkinson J, et al. The relationship between cigarette smoking and quality of life after lung cancer diagnosis. Chest 2004; 126: 1733-1741. 
Taylor KL, Cox LS, Zincke N, et al. Lung cancer screening as a teachable moment for smoking cessation. Lung Cancer 2007; 56: 125-134.

van der Aalst CM, van den Bergh KA, Willemsen MC, et al. Lung cancer screening and smoking abstinence: 2 year follow-up data from the Dutch-Belgian randomised controlled lung cancer screening trial. Thorax 2010; 65: 600-605.

Cox LS, Africano NL, Tercyak KP, et al. Nicotine dependence treatment for patients with cancer. Cancer 2003; 98: 632-644.

Sanderson Cox L, Patten CA, Ebbert JO, et al. Tobacco use outcomes among patients with lung cancer treated for nicotine dependence. J Clin Oncol 2002; 20: 3461-3469.

de Bruin-Visser JC, Ackerstaff AH, Rehorst $\mathrm{H}$, et al. Integration of a smoking cessation program in the treatment protocol for patients with head and neck and lung cancer. Eur Arch Otorhinolaryngol 2012; 269: 659-665.

Cooley ME, Wang Q, Johnson BE, et al. Factors associated with smoking abstinence among smokers and recent-quitters with lung and head and neck cancer. Lung Cancer 2012; 76: 144-149.

Cooley ME, Sarna L, Brown JK, et al. Tobacco use in women with lung cancer. Ann Behav Med 2007; 33: 242-250.

Schnoll RA, Malstrom M, James C, et al. Correlates of tobacco use among smokers and recent quitters diagnosed with cancer. Patient Educ Couns 2002; 46: 137-145.

Hughes JR, Stead LF, Lancaster T. Antidepressants for smoking cessation. Cochrane Database System Rev 2004; 1: CD000031.

Park ER, Japuntich S, Temel J, et al. A smoking cessation intervention for thoracic surgery and oncology clinics: a pilot trial. J Thorac Oncol 2011; 6: 1059-1065.

Wakefield M, Ruffin R, Campbell D, et al. Smoking-related beliefs and behaviour among adults with asthma in a representative population sample. Aust N Z J Med 1995; 25: 12-17.

Cerveri I, Cazzoletti L, Corsico AG, et al. The impact of cigarette smoking on asthma: a population-based international cohort study. Int Arch Allergy Immunol 2012; 158: 175-183.

Lange P, Parner J, Vestbo J, et

Zheng X, Guan W, Zheng J, et al. Smoking influences response to inhaled corticosteroids in patients with asthma: a meta-analysis. Curr Med Res Opin 2012; 28: 1791-1798.

Boulet LP, FitzGerald JM, McIvor RA, et al. Influence of current or former smoking on asthma management and control. Can Respir J 2008; 15: 275-279.

Chaudhuri R, Livingston $\mathrm{E}$, McMahon $\mathrm{AD}$, et al. Effects of smoking cessation on lung function and airway inflammation in smokers with asthma. Am J Respir Crit Care Med 2006; 174: 127-133.

Bush T, Zbikowski SM, Mahoney L, et al. State quitlines and cessation patterns among adults with selected chronic diseases in 15 states, 2005-2008. Prev Chronic Dis 2012; 9: E163.

Thomson NC, Chaudhuri R, Livingston E. Asthma and cigarette smoking. Eur Respir J 2004; 24: 822-833.

Van De Ven MO, van Zundert RM, Engels RC. Effects of asthma on nicotine dependence development and smoking cessation attempts in adolescence. J Asthma 2013; 50: 250-259. asthma. Am I Public Health 2000; 90: 1307-1311.

Piccillo G, Caponnetto P, Barton S, et al. Changes in airway hyperresponsiveness following smoking cessation: comparisons between Mch and AMP. Respir Med 2008; 102: 256-265.

Tønnesen P, Pisinger C, Hvidberg S, et al. Effects of smoking cessation and reduction in asthmatics. Nicotine Tob Res 2005; 7: 139-148.

Bateman ED, Hurd SS, Barnes PJ, et al. Global strategy for asthma management and prevention: GINA executive summary. Eur Respir J 2008; 31: 143-178.

British Thoracic Society, Scottish Intercollegiate Guidelines Network. British Guideline on the Management of Asthma. May 2008, Revised January 2012. http://sign.ac.uk/guidelines/fulltext/101/ Date last accessed: October 26, 2014.

Zumla A, George A, Sharma V, et al. WHO's 2013 global report on tuberculosis: successes, threats, and opportunities. Lancet 2013; 382: 1765-1767.

Mackay J, Crofton J. Tobacco and the developing world. Br Med Bull 1996; 52: 206-221. given during the 37th Union World Conference on Lung Health, Palais des Congres, Paris, France, 31 October-4 November 2006. Int J Tuberc Lung Dis 2007; 11: 1270-1271.

Brunet L, Pai M, Davids V, et al. High prevalence of smoking among patients with suspected tuberculosis in South Africa. Eur Respir J 2011; 38: 139-146.

Int J Tuberc Lung Dis 2013; 17: 1354-1357. sample. Tob Induc Dis 2013; 11: 8.

Pradeepkumar AS, Thankappan KR, Nichter M. Smoking among tuberculosis patients in Kerala, India: proactive cessation efforts are urgently needed. Int J Tuberc Lung Dis 2008; 12: 1139-1145.

Dhamgaye TM. Tobacco smoking and pulmonary tuberculosis: a case-control study. J Indian Med Assoc 2008; 106: $216-219$

Gajalakshmi V, Peto R. Smoking, drinking and incident tuberculosis in rural India: population-based case-control study. Int J Epidemiol 2009; 38: 1018-1025.

Gambhir HS, Kaushik RM, Kaushik R, et al. Tobacco smoking-associated risk for tuberculosis: a case-control study. Int Health 2010; 2: 216-222.

Wang J, Shen H. Review of cigarette smoking and tuberculosis in China: intervention is needed for smoking cessation among tuberculosis patients. BMC Public Health 2009; 9: 292.

Trifunović VS, Gvozdenović BS, Jovanovic D, et al. [Association between tobacco smoking and pulmonary tuberculosis]. Vojnosanit Pregl 2009; 66: 797-801.

Matsumoto K, Arima K, Komukai J, et al. [The association between smoking and sputum smear-positive pulmonary tuberculosis in Osaka City]. Kekkaku 2012; 87: 541-547. 
Bonacci RA, Cruz-Hervert LP, Garcia-Garcia L, et al. Impact of cigarette smoking on rates and clinical prognosis of pulmonary tuberculosis in Southern Mexico. J Infect 2013; 66: 303-312.

Horne DJ, Campo M, Ortiz JR, et al. Association between smoking and latent tuberculosis in the U.S. population: an analysis of the National Health and Nutrition Examination Survey. PLoS One 2012; 7: e49050. Maurya V, Vijayan VK, Shah A. Smoking and tuberculosis: an association overlooked. Int J Tuberc Lung Dis 2002; 6: 942-951.

Watkins RE, Plant AJ. Does smoking explain sex differences in the global tuberculosis epidemic? Epidemiol Infect 2006; 134: 333-339.

Davies PD, Yew WW, Ganguly D, et al. Smoking and tuberculosis: the epidemiological association and immunopathogenesis. Trans R Soc Trop Med Hyg 2006; 100: 291-298.

den Boon S, Verver S, Marais BJ, et al. Association between passive smoking and infection with Mycobacterium tuberculosis in children. Pediatrics 2007; 119: 734-739.

Leung CC, Lam TH, Ho KS, et al. Passive smoking and tuberculosis. Arch Intern Med 2010; 170: $287-292$.

Altet MN, Alcaide J, Plans P, et al. Passive smoking and risk of pulmonary tuberculosis in children immediately following infection. A case-control study. Tuber Lung Dis 1996; 77: 537-544.

Visser ME, Stead MC, Walzl G, et al. Baseline predictors of sputum culture conversion in pulmonary tuberculosis: importance of cavities, smoking, time to detection and W-Beijing genotype. PLoS One 2012; 7: e29588.

Fekih L, Boussoffara L, Abdelghaffar H, et al. Effet du tabagisme sur la tuberculose pulmonaire [Effect of tobacco smoking on pulmonary tuberculosis]. Rev Med Liege 2010; 65: 152-155.

Tachfouti N, Nejjari C, Benjelloun MC, et al. Association between smoking status, other factors and tuberculosis treatment failure in Morocco. Int J Tuberc Lung Dis 2011; 15: 838-843.

Gajalakshmi V, Peto R, Kanaka TS, et al. Smoking and mortality from tuberculosis and other diseases in India: retrospective study of 43000 adult male deaths and 35000 controls. Lancet 2003; 362: 507-515.

Jiang J, Liu B, Nasca PC, et al. Smoking and risk of death due to pulmonary tuberculosis: a case-control comparison in 103 population centers in China. Int J Tuberc Lung Dis 2009; 13: 1530-1535.

Wen CP, Chan TC, Chan HT, et al. The reduction of tuberculosis risks by smoking cessation. BMC Infect Dis 2010; 10: 156 .

Jee SH, Golub JE, Jo J, et al. Smoking and risk of tuberculosis incidence, mortality, and recurrence in South Korean men and women. Am J Epidemiol 2009; 170: 1478-1485.

Lin HH, Ezzati M, Chang HY, et al. Association between tobacco smoking and active tuberculosis in Taiwan: prospective cohort study. Am J Respir Crit Care Med 2009; 180: 475-480.

Siddiqui UA, O’Toole M, Kabir Z, et al. Smoking prolongs the infectivity of patients with tuberculosis. Ir Med J 2010; 103: 278-280.

Lavigne M, Rocher I, Steensma C, et al. The impact of smoking on adherence to treatment for latent tuberculosis infection. BMC Public Health 2006; 6: 66.

PrayGod G, Range N, Faurholt-Jepsen D, et al. Sex, smoking, and socioeconomic status are associated with body composition among tuberculosis patients in a deuterium dilution cross-sectional study in Mwanza, Tanzania. J Nutr 2013; 143: 735-741.

Underner M, Perriot J. Tabac et tuberculose [Smoking and tuberculosis]. Presse Med 2012; 41: 1171-1180.

Xie ZY. [A study of blood rifampin concentration in smoking and non-smoking healthy individuals and in patients with tuberculosis]. Zhonghua Jie He He Hu Xi Za Zhi 1989; 12: 3-5, 60.

Kolappan C, Gopi PG. Tobacco smoking and pulmonary tuberculosis. Thorax 2002; 57: 964-966.

Ng N, Padmawati RS, Prabandari YS, et al. Smoking behavior among former tuberculosis patients in Indonesia: intervention is needed. Int J Tuberc Lung Dis 2008; 12: 567-572.

Shin SS, Xiao D, Cao M, et al. Patient and doctor perspectives on incorporating smoking cessation into tuberculosis care in Beijing, China. Int J Tuberc Lung Dis 2012; 16: 126-131.

Amara B, El Ghazi K, Rahimi H, et al. Attitudes et connaissances des pneumo-phtisiologues marocains vis-a-vis du tabagisme chez leurs patients tuberculeux [Attitudes and knowledge about smoking among Moroccan physicians looking after patients with tuberculosis]. Rev Mal Respir 2008; 25: 569-575.

Sereno AB, Soares EC, Lapa ESJR, et al. Feasibility study of a smoking cessation intervention in Directly Observed Therapy Short-Course tuberculosis treatment clinics in Rio de Janeiro, Brazil. Rev Panam Salud Publica 2012; 32: 451-456.

Siddiqi K, Khan A, Ahmad M, et al. Action to stop smoking in suspected tuberculosis (ASSIST) in Pakistan: a cluster randomized, controlled trial. Ann Intern Med 2013; 158: 667-675.

Awaisu A, Haniki Nik Mohamed M, Noordin NM, et al. Impact of connecting tuberculosis directly observed therapy short-course with smoking cessation on health-related quality of life. Tob Induc Dis 2012; 10: 2.

Enarson DA, Slama K, Chiang CY. Providing and monitoring quality service for smoking cessation in tuberculosis care. Int J Tuberc Lung Dis 2007; 11: 838-847.

Thompson DR, Chair SY, Chan SW, et al. Motivational interviewing: a useful approach to improving cardiovascular health? J Clin Nurs 2011; 20: 1236-1244.

Asfar T, Ebbert JO, Klesges RC, et al. Do smoking reduction interventions promote cessation in smokers not ready to quit? Addict Behav 2011; 36: 764-768.

Bolliger C, Zellweger CP, Danielson T, et al. Influence of long-term smoking reduction on health risk markers and quality of life. Nicotine Tob Res 2002; 4: 433-439.

4 Hughes JR, Solomon LJ, Livingston AE, et al. A randomized, controlled trial of NRT-aided gradual vs. abrupt cessation in smokers actively trying to quit. Drug Alcohol Depend 2010; 111: 105-113.

Hatsukami DK, Rennard S, Patel MK, et al. Effects of sustained-release bupropion among persons interested in reducing but not quitting smoking. Am J Med 2004; 116: 151-157.

6 Hughes J, Rennard S, Fingar J, et al. Efficacy of varenicline to prompt quit attempts in smokers not currently trying to quit: a randomized placebo-controlled trial. Nicotine Tobacco Res 2011; 13: 955-964.

Shiffman S, Ferguson SG. Nicotine patch therapy prior to quitting smoking: a meta-analysis. Addiction 2008; 103: 557-563.

Fiore MC, Baker TB. Clinical practice. Treating smokers in the health care setting. N Engl J Med 2011; 365: $1222-1231$. 
159 Lindson N, Aveyard P. An updated meta-analysis of nicotine preloading for smoking cessation: investigating mediators of the effect. Psychopharmacology 2011; 214: 579-592.

160 Hajek P, McRobbie HJ, Myers KE, et al. Use of varenicline for 4 weeks before quitting smoking: decrease in ad lib smoking and increase in smoking cessation rates. Arch Intern Med 2011; 171: 770-777.

161 Koegelenberg CF, Noor F, Bateman ED, et al. Efficacy of varenicline combined with nicotine replacement therapy vs varenicline alone for smoking cessation: a randomized clinical trial. JAMA 2014; 312: 155-161.

162 Hajek P, Smith KM, Dhanji AR, et al. Is a combination of varenicline and nicotine patch more effective in helping smokers quit than varenicline alone? A randomised controlled trial. BMC Med 2013; 11: 140.

163 Ebbert JO, Hatsukami DK, Croghan IT, et al. Combination varenicline and bupropion SR for tobacco-dependence treatment in cigarette smokers: a randomized trial. JAMA 2014; 311: 155-163. 